\title{
Proximity tourism: A thematic literature review
}

Tarja Salmela, post doctoral researcher, University of Lapland, Multidimensional Tourism Institute Henna Nevala, University of Lapland, Northern Tourism

Minna Nousiainen, University of Lapland, Northern Tourism

Outi Rantala, associate professor, University of Lapland, Multidimensional Tourism Institute

\section{Abstract}

This literature review aims to build an understanding of the emerging analytical discussions appearing in the research published on the topic of proximity tourism within the tourism and hospitality literature. In addition to referring to a particular form of tourism that emphasises local destinations, short distances and lower-carbon modes of transportation, proximity tourism builds upon an idea of seeing our proximate, everyday surroundings anew. Despite the currency and relevance of the topic of proximity, the existing literature on proximity tourism is relevantly scarce. In addition, there is variance in the usage of concepts referring to proximity tourism. With these notions forming the motivation for our study, we conducted a thematic literature review of international research publications concerning the topic at hand. We identified a considerable potential in this emerging strand of research of proximity tourism to renegotiate tourism, its concepts and future(s). By re-examining the dichotomy between tourist and local; challenging the definition of tourism on the basis of distance as 'nearness' and 'farness' and; envisioning brave new tourism futures, the reviewed research literature of proximity tourism disrupts the very basic concepts of tourism. The existing literature of proximity (in) tourism is thus able to create space for new conceptualisations within tourism studies that make way for the plurality of tourism futures.

Keywords: proximity tourism, intraregional tourism, nearhome tourism, hometown tourism, staycation 


\section{Introduction}

Proximity tourism has gained increasing attention during the last year, not only because of the ongoing COVID-19 pandemic but also due to increased awareness of the impacts of climate change and the urgency of the environmental crisis we are facing. Despite the relevance of the topic of proximity, the existing literature in tourism and leisure studies on proximity tourism is relevantly scarce. Hence, the purpose of this literature review is to gain an understanding of the emerging research related to the topic of proximity tourism within the tourism and hospitality literature.

Proximity tourism refers to a particular form of tourism that emphasises local destinations, short distances and lower-carbon modes of transportation (Jeuring \& Diaz-Soria, 2017). Yet, proximity tourism is not only about distance - it is a form of tourism that is built upon the idea of seeing proximate, everyday surroundings anew (Rantala et al., 2020). Indeed, the concept of proximity challenges the traditional way of defining tourism on the basis of nearness and farness, or through the interplay of the ordinary and extraordinary (Höckert et al. forthcoming; Urry, 2002). Therefore, our mission in this review is to welcome alternative conceptualisations and theoretical approaches to investigate proximity in tourism.

With this scope and focus, a selection of 24 research articles were included in the collection under review. The review process is detailed in the following section. The publications are then thematised under five themes: construction of (touristic) otherness; tourism mobilities; proximity-oriented tourism services and marketing strategies; everyday/mundane aesthetics of proximity (tourism); and alternative future(s) of tourism. Thus, the main focus is to make visible the existing understandings related to proximity in tourism and to discuss the potentiality of the identified themes, instead of comprehensively summarise the contents of the selected articles. We end the review with a discussion of the implications of the paper for the expansion of the conceptual, methodological and theoretical approaches to "proximity" within tourism studies.

\section{Data gathering process: search terms, databases and the selection of articles}

In a Finnish context, the phenomenon of proximity tourism (in Finnish lähimatkailu) is widely acknowledged in media and marketing materials. Yet what is less clear is whether the concept has found its way to the vocabulary of Finnish tourism research. During the preliminary background work conducted before a more systematic review, we were convinced of the scarcity of Finnish peer-reviewed research concerning proximity tourism. However, the phenomenon has been discussed previously in this journal in the context of everyday consumption (Räikkönen et al., 2018) and in relation to nature affording wellbeing (Rantala \& Puhakka, 2019). Our literature review thus focuses on international research publications on the topic that are written in English and are accessible to wider audience.

As the phenomenon under investigation is clearly a tourism and travel related phenomenon, we have focused particularly on the tourism and hospitality literature (cf. Nuottila et al., 2017 in this journal). Nonetheless, the selection of articles for review was not unproblematic. 
As there were many phenomena related to that of proximity tourism within tourism research and practice, a constant reminder of the aim of the review had to be set. For example, during the data gathering process, we identified a large amount of research focusing on cross-border tourism and second-home tourism. This strand of research did yet not answer to our quest for building an understanding of the emerging analytical discussions appearing in the research and welcoming alternative conceptualisations and theoretical approaches to investigate proximity in tourism. Thus, we wanted neither to narrow the search excessively nor to get stuck with already established notions and concepts that describe a certain already well-established strand of research (such as second-home tourism).

In addition, the search was narrowed to academic articles published in the journals relevant to the field of research at hand in order to limit the review into peer-reviewed research and because of the utilisation of limiting the search to "Articles" in the databases.

\section{Search terms}

The formation of relevant search terms regarding proximity tourism started by dividing the phenomenon under investigation into thematic groups (e.g. first, tourism to point both to the phenomenon of tourism and travel and means of traveling; second, tourist(s) pointing to the executors/participants of tourism and travel; third, proximity/proximate to point to the characteristic of the particular form of tourism under investigation, and; fourth, destination(s) to point to the destination of proximate tourism taking place). Within the relevant search terms there were also indefinite terms. For example, in the very first phases of the process, we had to decide whether or not to include the search term "domestic". This question comes down to the challenging and never neutral definition of proximate: what is considered proximate, and from what point of view? We ended up not including domestic travel/tourism in the search. This choice was justified by the fact that domestic travel can include relatively long-distance travel (e.g. travel from the capital of Finland, Helsinki, to Rovaniemi, which encompasses more than $800 \mathrm{~km}$ ), and the literature considering domestic tourism is vast and does not provide an understanding of the particular phenomenon we are investigating (proximity tourism). In addition, the motivation to exclude "local" from our search terms stemmed from the presence of results in our test searches that emphasised the point of view of locals participating in the development/ design of tourism supply in a chosen area. This orientation means that the results did not address "locality" from the point of view of local areas as a site for proximate tourism practices or proximate tourism experiences.

We used the thesaurus and ontology service EBSCO Thesaurus Hospitality \& Tourism Complete for a detailed exploration of search terms. The quest to find search terms that would equal "proximate" was challenging. Proximate, intraregional, intra-regional, near-home, nearby, near(-)by, short(-)distance and home(-)bound were not found in EBSCO Thesaurus Hospitality \& Tourism Complete. The EBSCO databases did however provide search terms with an automatic suggestion related to proximity: closeness or distance. Multiple trial searches were conducted using the narrower terms concerning tourism identified during the search and connecting them with 
proximity, closeness and distance, using Scopus as a trial database. ${ }^{1}$ These searches led to over 3000 research results with a variety of irrelevant articles. Trial searches were also conducted using the general terms "tourism" and "travel" combined with search terms equal to "proximity", prompting tens of thousands of search results. A search was done with exclusions based on the identification of repeatedly irrelevant research results and their common denominators. Despite these efforts, the search results were still too wide in both scope and number and formed an inconsistent picture of the research. After this outcome, the search was replanned to focus more strictly on the phenomenon under investigation by using closed compounds. The following search was conducted in SCOPUS:

TITLE-ABS-KEY ("proximity tourism" OR "intraregional tourism" OR "nearhome tourism" OR "hometown tourism" OR "proximate traveller" OR "intraregional traveller" OR "nearhome traveller" OR "hometown traveller" OR staycation)

\section{Selection of articles}

Limiting the search to journal articles in the English language prompted 115 results in SCOPUS. Sorted by relevance, the articles were scanned and a selection process was conducted. For example, articles concerning "slow travel" that did not have an emphasis on proximity/near-home tourism were excluded. Similarly, articles concerning tourism after or during COVID-19 were identified but not selected for further investigation unless they had a focus or emphasis on proximity/near-home tourism. Altogether, 14 relevant articles were selected for further investigation from the first database. The same search and selection process was then conducted across EBSCO, CABI, LUC Finna and Google Scholar. A total of 30 articles were included for further review. In addition, a complementary search was done in all the aforementioned databases by using the search phrase (in Scopus' search mode): "proximity" OR "intraregional" OR "nearhome" OR "hometown" AND TITLE-ABS-KEY (vacation OR holiday). This search was meant to identify potential publications that would focus on the concepts of vacation or holiday instead of tourism. No relevant articles were found in any of the databases based on this search beyond those already found in the main search.

Finally, of the existing 30, five (5) were excluded based on either the discovery of their form as a book chapter (1) or dissertation (1) instead of an academic article or their publishing journal not being convincingly peer-reviewed (3). ${ }^{2}$ The group of articles chosen for a more detailed review thus consisted of 25 articles. Additional relevant articles that were potentially left out of our search scope were sourced from the reference lists of the chosen articles. These articles were checked to determine whether they fulfil the criteria for the review. Five articles were added. ${ }^{3}$

1 The choice to use Scopus instead of EBSCO database was justified by the fact that Scopus allows the narrowing of the search to title, abstract and keywords (in contrast to EBSCO search, where a selection has to be made between the title and abstract, for example).

2 Alexander et al. (2011); Bissel (2018); Cvelbar \& Ogorevc (2020); Jeuring (2017); Pawlowska-Legwand \& Matoga (2016).

3 Canavan (2013); Chen \& Chen (2017); Griffin (2017); Larsen \& Guiver (2013); Richards (2016). 
The whole collection of articles was double-checked to ensure they match the criteria of review. This phase led to the exclusion of five (5) articles ${ }^{4}$ based on the discovery of their publication in non-peer reviewed journals or of content outside scope of the review. In addition, two articles were excluded because they were only available in other languages than English.5 Tourism Geographies' "Proximity and intraregional aspects of tourism" (2017) special issue included two publications that had not shown up in the database searches (Biddulph, 2017; Kaaristo \& Rhoden, 2016). These articles were familiarised and evaluated, and the decision was made to include one of these articles (Kaaristo \& Rhoden, 2016) in the review. ${ }^{6}$ Thus, a selection of 24 research publications formed the final content of the literature review.

\section{Literature review}

The special issue "Proximity and intraregional aspects of tourism" (2017) of Tourism Geographies played a role in the way we thematised the chosen articles. Jeuring and Diaz-Soria (2017) describe the goal of the 2017 special issue's collection of articles to "cover a range of examples of tourism practices in a context of geographical proximity where home and away, everyday life and tourism intersect" (p. 6). Thus, instead of providing examples of something universally conceptualised as proximity tourism, the special issue's contributions represent "an attempt to rethink the hegemonic linear framing of tourism in dichotomies such as familiar and unfamiliar, nearby and far, host and guest, mundane and exotic" (p. 6). Although we recognised the value of the special issue, we noted that in the time of the global COVID-19 pandemic an updated thematisation was clearly needed, not least because some of the publications (e.g. Romagosa, 2020) included in our literature review deal directly with post-pandemic tourism, five were published after the special issue of Tourism Geographies, and some were published in the same year.

Thus, after an iterative work process, five (overlapping) themes appeared as the most comprehensive in terms of encompassing the spectrum of articles under review: otherness in tourism; tourism mobilities; proximity-oriented tourism services and marketing strategies; everyday/mundane aesthetics of proximity (tourism); and alternative future(s) of tourism (see Table 1). We will next introduce the contents of the review through this thematisation. In the table 1, we have divided the articles to "articles discussing the theme" and "articles related to theme". This division is to help the readers acknowledge those articles that build deep insight of a specific theme, and the articles that are strongly related to the theme, yet belonging to another theme as their primary content and focus of research. We recognize the overlapping character of the themes and consider it in point of fact a necessity when discussing a complex phenomenon of proximity in tourism. Furthermore, we hope that the table gives the readers an easy access to the themes and the related research articles.

4 Algassim (2021); Couret (2020); Kennedy (2009); Nemec-Loise (2014); Pokorny et al. (2017).

5 Hugues (2009); Llurdés et al. (2016).

6 The decision to exclude Biddulph's (2017) article from the review resulted from the particular focus of the study in investigating the foothold of tourism stakeholders at the edge of an expanding mass tourism centre, thus focusing on back-region tourism territorialisation and the local economy in a poor province in Cambodia and not having the specific focus on discussing proximity tourism or proximity that forms the focus of this review. 
Table 1. Thematisation of articles*.

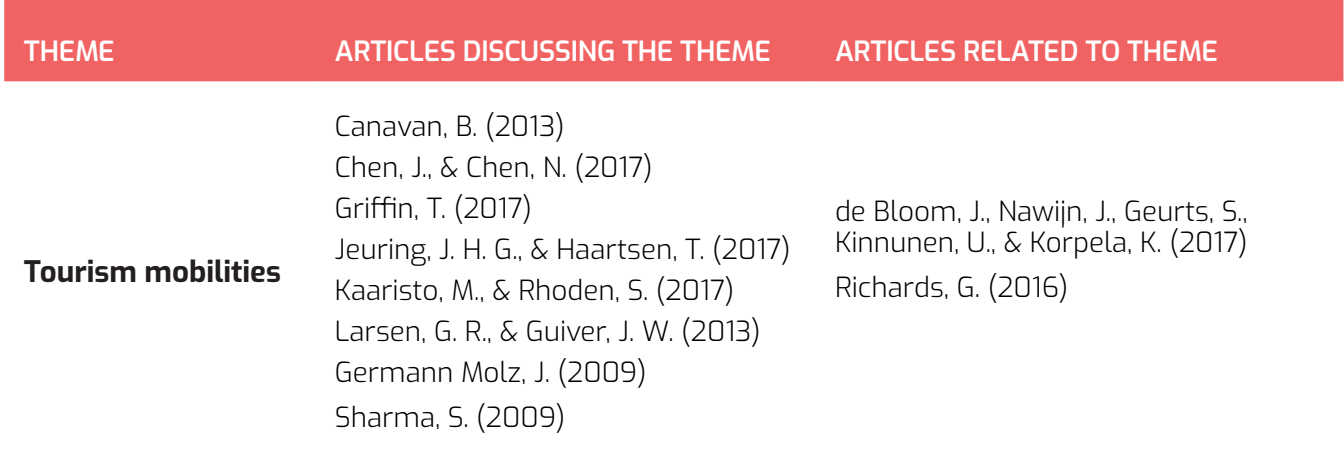

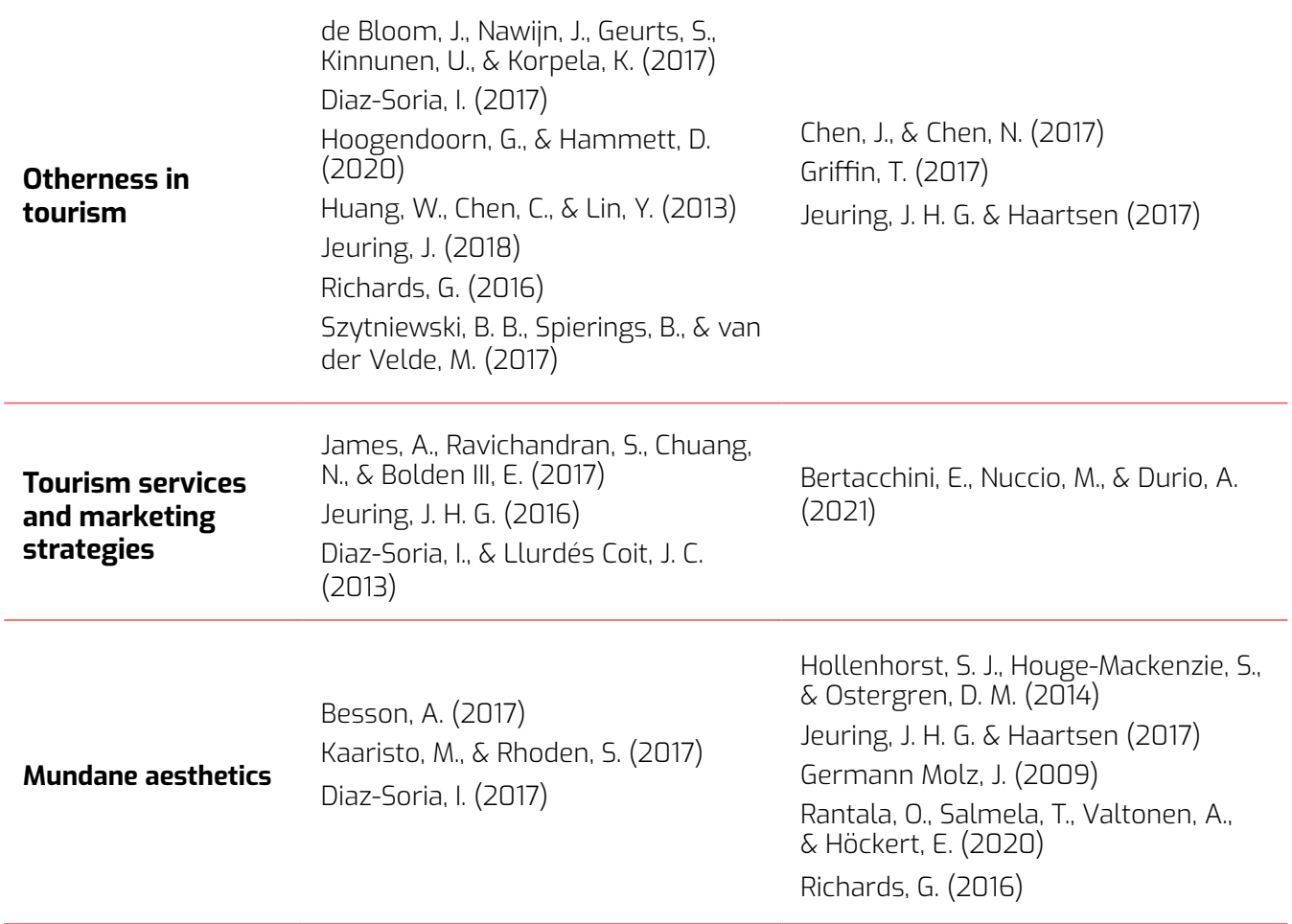

Hollenhorst, S. J., Houge-Mackenzie,

S., \& Ostergren, D. M. (2014)

Future(s) of tourism Rantala, O., Salmela, T., Valtonen, A.,

\& Höckert, E. (2020)

Romagosa, F. (2020)

*In addition: Jeuring, J., \& Diaz-Soria, I. (2017) was not thematised under any theme due to its introductory nature. 


\section{Tourism mobilities}

The reviewed articles deconstruct the conception of tourism mobilities as being structured merely through notions of physical distance or as mobilities outside our everyday surroundings. Instead, they invite us to re-examine tourism mobilities as part of mundane environments and practices shaping our perceptions of place and blurring the previously prevailing dichotomies of exotic and mundane, home and away, near and far or business and pleasure. They also discuss the ways in which representations of pace impact and shape mobility practices in tourism. In doing so, the authors provide new approaches for understanding the potentiality of proximity (tourism).

Chen and Chen (2017) see tourism mobilities as mediators between different places and people. They demonstrate how the meanings of tourist sites are constantly reconstructed and communicated in the daily lives of the visitors. Various mundane tasks are performed in parallel with holiday environments, revealing the "in-betweens of tourist life" as described by Kaaristo and Rhoden (2017) in their study of holiday boaters' mundane practices. Furthermore, as a result of accelerated global mobility, people are increasingly engaged with tourism practices in their everyday environments (Griffin, 2017; Richards, 2016). They take different roles, from hosts to tourists, or simply transfer practices from their holiday experiences to their daily lives. As a result, they are continuously renegotiating place meanings as well as their personal relationship with the mundane world. Thus, tourism mobilities are diminishing the perception of distinct tourist sites as they are highlighted in the narratives of tourism marketing, simultaneously portraying the potential of our proximate environments. As suggested by Jeuring and Haartsen (2017, p. 118), proximity can become a new commodity.

Larsen and Guiver (2013) as well as Jeuring and Haartsen (2017) approach the potentiality of proximity tourism by studying people's understanding of distance in the context of holiday mobility. The findings of the study indicate that people tend to perceive distance as a relative dimension, emphasising experience over physical distance and making the journey (either physical or mental) itself relevant to understanding the meaning of that distance. Differences, for example, in landscapes, infrequency of visits and time spent on traveling are all factors that can produce similar feelings of escapism, novelty and contrast to those evoked by travel to more distant places (Canavan, 2013). This similarity encourages us to approach distance and mobility as an integral part of the holiday experience rather than a necessary transition between home and the destination. Furthermore, it emphasises the role of movement in the experience and recommends modes of travel that enable a closer connection with the surrounding nature and a deeper engagement with the relative dimensions of distance (de Bloom et al., 2017; Larsen \& Guiver, 2013).

While the articles discussing mobility demonstrate new dimensions for understanding mobilities and proximity in the context of tourism, they also reveal the challenge that proximity and alternative understandings of mobility pose for the circulation of capital and for global mobility. This challenge reflects, for example, on representations of pace (Germann Molz, 2009), which have predominantly portrayed speed and acceleration as normal forms of mobility, as embodiments of freedom and modernity. In this dichotomy, slowing down or staying still are presented 
as something abnormal. The values mediated through these representations have an influence on our mobile practices and as such may become questions of politics and power. Sharma (2009) illustrates this problematic approach vividly in her article discussing the consequences of the economic slowdown of 2008, which forced people to stay at home. The thread of immobility created the marketable concept of the staycation, with new commodities being produced in order to keep capital and households in motion instead of seeing the potentiality of different associations of pace for alternative mobility practises (Germann Molz, 2009; Sharma, 2009).

\section{Otherness in tourism}

Touristic otherness links closely to (new) tourism mobilities through the blurring of the boundary between the exotic and the mundane. The tension between exotic and mundane, for its part, invites questions regarding what is considered normal or familiar and what instead is abnormal, strange and other-than in a tourism context. Richards (2016) notes how tourism can no longer be considered visiting places outside the "normal" environment, as "the nature of modern urban living means that the concept of 'normal environment' is changing as well" (p. 9). This change of the normal poses a need for a commitment to reconsideration instead of a re-affirmation of the dominant logics of tourism - a commitment that the reviewed articles manifest by making a valuable contribution towards a more complex understanding of what is understood by the concepts of tourist, tourism and tourism sites or places than the dominant tourism discourse is able to provide.

In practice, the reviewed articles not only challenge the conceptual tourist-local dichotomy dominating the tourism discourse (Richards, 2016) but also offer a more nuanced understanding of what is actually meant by 'tourist' (Diaz-Soria, 2017; Hoogendoorn \& Hammett, 2020). The articles re-evaluate the role of residents in touristic production and consumption (Jeuring, 2018) as well as provide a basis for an expanded understanding of distance. Distance works as an essential element of tourism in the search of respite from work, and as such it plays a part in the processes of othering (de Bloom et al., 2017; see also Larsen \& Guiver, 2013). The articles also highlight the particularities of the interpretation of the exotic and the mundane in a cross-border context (Szytniewski et al., 2017).

A common denominator in the reviewed articles is an understanding of tourism, tourists and tourism sites as entangled with mundane life. According to this understanding, the other is no longer constructed via experiences encountering a strange, new culture in a far-away travel location (a tourist space) that the tourist is observing and consuming (see Richards, 2016, p. 9). The formation of otherness is thus not based on a temporal escape from the reality of what is waiting back home. Instead, tourist places can turn from an "antithesis of mundane society" to a "home away from home" (Chen \& Chen, 2017, p. 16). Alternatively, the home (city, village, neighbourhood) can itself turn into a site for tourism (Diaz-Soria, 2017; Hoogendoorn \& Hammett, 2020). In a cross-border context, Szytniewski et al. (2017) argue, the relationship between home and away is even more foregrounded "as tourists face geographically 'close' but assumingly socially and culturally 'distant' people and places” (p. 64). 
Jeuring (2018) notes how the concept of proximity tourism in itself indicates the heterogeneity of the roles local residents play in relation to the place's role as a tourism destination. This heterogeneity means that "residents can experience a city, region or country both as a tourist and as a resident" (Jeuring, 2018, p. 148), making the aforementioned dichotomies between locals and tourists not only irrelevant but implausible. Diaz-Soria (2017) investigate the construction of otherness among locals in a familiar environment during guided walking tours in Barcelona. Her study makes visible that the intentional adoption of a tourist gaze by locals reflects an already "identified otherness in [the locals'] perimeter of proximity" in relation to their home city (p. 113). The participants of the guided walking tour thus engaged in rituals of touristic consumption, which in modern urban living can be enjoyed everywhere (Richards, 2016, p. 9).

Touristic practices in proximate environments, such as guided walking tours, can in themselves represent "an experience of the otherness" (Diaz-Soria, 2017, p. 113). This otherness is based on the possibility of a confrontation with the unknown or something surprising, approached with curiosity. The reviewed articles demonstrate how otherness can stem from the experience of being the other in a touristic setting as well as from positioning oneself as an observer of the other(s). Depending on the context, the other does not always have to concern intercultural encounters or physical surroundings; it can be as simple as "different products, prices and atmosphere", as in shopping tourism (Szytniewski et al., 2017, p. 64). All these experiences involve a reflexive space for (sometimes unexpected) encounters, be they with people, cultures, materiality, atmosphere, nature or even conceptions of time and pace (see Germann Molz, 2009).

In the processes of othering, play between the strange and familiar is vivid and constantly evolving. Some of the reviewed articles highlight the nature of particular places and sites as holding elements of the fluctuation between the strange and the familiar (instead of focusing on personified tourist/local subjects experiencing these sites). With an emphasis on tourism flows in geographically proximate places, Huang et al. (2013) investigate how Taiwan is considered culturally familiar and at the same time mysterious by its visitors because of its previous travel restrictions and the political tensions characterising the destination. Chen and Chen (2017), however, make an important remark on the non-universal nature of experiences at a particular touristic site. The authors illustrate how the meanings of tourism sites are actively interpreted, modified and renegotiated by the travellers themselves, and as such are never stable. In line with the evidence provided by previous studies, this conclusion conflicts with traditional tourism marketing and brand work, which leans on a simplified image of tourism destinations and is supported by governments (Huang et al., 2013.)

Processes of othering also bring about questions of (in)equality and colonialism: who has a permission to observe and experience the other with a tourist's gaze? As such, processes of othering reflect wider geographical and political developments of human-inhabited cities, such as the emergence of "no-go" or restless areas within urban cities, such as those in Johannesburg (Hoogendoorn \& Hammet, 2020). In these developments, an area of a city and its residents can turn into a tourist destination and sight, consumed by residents (who are, to a degree, privileged) from other (safer) parts of the city. These "resident tourists" (Hoogendoorn \& Hammett, 2020) feel protected when exploring this "other" part of the city together with one another, bonding and networking with each other (thus forming together "an other"). This privileged group of 
resident tourists might additionally utilise digital sociality, such as social media, for the collective practice of the tourist gaze.

\section{Proximity oriented tourism services and marketing strategies}

Although the tourism literature concerning the development of new tourism services and marketing strategies has focused prominently on external tourism flows, the current proximity-oriented literature has started to acknowledge the possibilities related to the development of tourism services and marketing for local and intraregional tourists. A significant number of articles included in our review explore the potential that nests in local residents when it comes to increasing tourist flows, providing insights into tourist behaviour (Bertacchini et al., 2021) and increasing the value of usual environments (Diaz-Soria \& Llurdés-Coit, 2013). In addition, they highlight the importance of widening knowledge about this often overlooked tourism practice as a part of the tourism economy, and they approach proximity with the intention to strengthen its position in regional destination marketing (Bertacchini et al., 2021; Jeuring, 2016).

But why should tourism marketing strategies include tourists that live near these destinations and tourism services? Although tourism marketing strategies and place branding initiatives are often targeted to tourists coming from abroad, in several countries intraregional and domestic tourists are generating more income, especially long term (Jeuring, 2016). Likewise, proximity tourism can also work as a strategy to tackle some of the prominent issues in the field, such as seasonality and the loss of and disregard for local heritage (Diaz-Soria \& Llurdés-Coit, 2013). According to a study on contradicting discourses in marketing strategies by Jeuring (2016), the vast majority of visitors to Frisian destinations come from the same region or other nearby areas, yet the destination marketing strategy does not include any specific strategy for targeting intraregional tourists. If marketing strategies are increasingly focusing on international tourist groups and continue to disregard the demands and preferences of tourists that live inside the region, it could potentially destabilise certain destinations' identities (Jeuring, 2016). One could argue that this shift might further result in a decrease of interest from their biggest target group.

As noted in many of the previous proximity-oriented studies here, tourism scholars are calling to redefine the assumptions that are tied to tourism practices in order to respond to new and everchanging tourist demands (Diaz-Soria \& Llurdés-Coit, 2013). Changes in the economy, such as the 2008 recession, turned tourism marketers' gaze towards proximity tourism as a possible alternative for international tourism, as it is a more affordable and equally accessible way of traveling between different areas in the same region (Bertacchini et al., 2021; James et al., 2017). In this sense, proximity tourism could additionally be perceived as a way to foster equality between people with different social classes, as this way of traveling enables people with lower incomes to gain tourism experiences even though they might not be able to afford to travel to faraway destinations.

Studies focused on marketing and proximity tourism offer valuable viewpoints and ideas that tourism operators and marketers can utilise when developing their services and marketing strategies. The segmentation and profiling of possible staycation travellers to create packages for lodging providers (James et al., 2017) and the surveying of tourist demands, motivations and 
needs (Diaz-Soria \& Llurdés-Coit, 2013; Jeuring, 2016) are just a couple of the ways in which these studies guide how and why proximity tourism should be included in regional tourism planning. A study conducted by Bertacchini et al. (2021) explores the extent to which regional museum cards directed to local residents can promote local destinations and increase visitor flow towards marginalised and often overlooked cultural facilities and conveniences. It seems that including the proximity sphere in marketing strategies could enable the rediscovery and creation of new meanings for parts of local heritage that have been disregarded or that have lost their original meaning (Diaz-Soria \& Llurdés-Coit, 2013). Furthermore, as stressed by Bertacchini et al. (2021), marketing of proximity tourism should emphasise the diversity of experiences available and explore intraregional destinations and the opportunities they possess. Perhaps this approach could be an efficient way of recreating value for culturally valuable assets that might otherwise be dismissed or even disappear.

\section{Everyday/mundane aesthetics of proximity (tourism)}

Aesthetics are an essential aspect of holiday experiences, which are commonly seen as aesthetic pastimes in aesthetically appealing locations (Besson, 2017, p. 35). The reviewed articles, however, invite us to approach aesthetics in the mundane world around us. Questions of everyday aesthetics in the context of proximity tourism can be coupled with experiences of otherness and the ways people come to perceive their familiar and proximate environments as attractive (Jeuring \& Haartsen, 2017). In the end, aesthetics are experienced in the ways we relate with our surroundings.

Applying Tuan's (1990) theory, Diaz-Soria (2017) notes that engagement with everyday surroundings through touristic practices could bring increased awareness to the aesthetic elements around us. A conscious construction of otherness by applying a tourist's gaze, the ability to wonder, may shift our approach from the typically prevailing functional meanings of our everyday environments into appreciating the aesthetic value of them and, as such, can provide new ways of renegotiating place meanings. Mundane everyday practices, such as preparing a regular dinner, may become an extraordinary experience if enjoyed in an aesthetically appealing or novel environment (Kaaristo \& Rhoden, 2017), constructed by "imitating" touristic consumption or applying tourist strategies at home (Richards, 2016). Thus, taking pictures, enjoying culinary experiences and tuning into landscapes or details are strategies that provide us with opportunities to enhance aesthetic experiences of both mundane tasks and mundane environments.

Supporting this viewpoint, Besson (2017) suggests that distance is not a prerequisite for the restorative aesthetic experience that is typically linked with holidays. In her study, Besson analyses lifestyle articles and social media photographs on the phenomenon of staycation. The data reveals a strong emphasis on content with beautiful landscapes, cultural attractions or gastronomic experiences. The photographs suggest participation in restorative activities similar to those from a holiday and the carefully composed content mediates the aesthetic intentions or reactions that staycationers connect with their experiences. Thus, the study implies that staycation is a strategy to enhance aesthetic sensitivity while engaging with activities, objects or environment that are perceived as aesthetic (p. 46). 
Increased aesthetic sensitivity within the ordinary can also have significant impacts on tourism practices, mobilities and the ways we engage with our everyday environments. Slow travel, for example, is often perceived as an aesthetic mode of travel, as it allows us to immerse ourselves in our surroundings in a more profound way. In doing so, it also appeals to concerns surrounding environmental sustainability and encourages us to travel locally or to stay still (Germann Molz, 2009, p. 280). Furthermore, changing our perspective from the mere functionality of our mundane surroundings to their aesthetic value may enhance our commitment and care for local places and environments, as well as allow us to sensitise ourselves towards the ordinary more-than-human world around us (see Hollenhorst et al., 2014; Rantala et al., 2020).

\section{Alternative future(s) of tourism}

The reviewed articles also envision tourism anew by going beyond evaluating or mapping the current state of proximity tourism. They see an urgent need for change and the potential of proximity in fuelling that change. For example, Hollenhorst et al. (2014) problematise tourism's foundational idea of traveling to faraway destinations in search of new experiences. According to the authors, the trouble with tourism is manifold - the idea of having to go far away to experience something that is considered valuable takes something away from our commitment to local places, making them seem potentially less valuable to care for or too mundane for exceptionality. Hollenhorst et al. (2014) see the potential in proximity tourism -- in the form of locavism or bioregional tourism - for investing and connecting with local communities. For his part, Romago$\mathrm{sa}(2020)$ links the potential of proximity tourism to the ability of the tourism sector to overcome the current COVID-19 pandemic.

New ways of understanding tourism, potentially through care, rhythmicity or vitality, as suggested by Rantala et al. (2020), are needed to answer the challenges we are acutely aware of - not only the ongoing pandemic, but also climate change, to which tourism sector itself is contributing (Hollenhorst et al., 2014). This problem also requires us to evaluate anew the central, seemingly stable and fixed notions of sustainability or responsibility, which tend to narrow down the opportunities for creating new solutions and practices to create more ecologically and socially sustainable tourism futures. Romagosa (2020) sees resilience as a central concept when rethinking the sustainability of tourism. Rantala et al. (2020) point out that sustainability discourses are associated with concepts that rely on business-oriented thinking and growth paradigms. The authors offer proximity - and locavism (Hollenhorst et al., 2014) - as alternative ways to address our practice tourism in the future. This future of tourism is considered downto-earth and rooted, rather than flying high up in the air and structured around the idea of a globally disconnected, nomadic subject. Places are allocated meaning (Hollenhorst et al., 2014), and the focus is not on measuring what is proximate in a universal sense - a philosophical starting point embraced in feminist science (Rantala et al., 2020). Hence, proximity invites a deeper, grounded, slower and thoughtful engagement with place.

This down-to-earth perspective does not conflict with bold, even radical ideas concerning the future(s) and practice(s) of tourism. Instead, the articles acknowledge the need for radical interventions to disrupt the normal in tourism. In these research openings, the role of an air travel-dominated tourism industry in the creation of climate change (Hollenhorst et al., 2014) 
and social inequalities (Romagosa, 2020) is acknowledged. Furthermore, the idea of tourism as a sustainable, alternative option for extractive industries is questioned (Hollenhorst et al., 2014). However, the authors suggest developing proximity tourism not as a distinct new dimension of tourism, but rather as a way of transforming habituated ways of thinking about and practising tourism (Rantala et al., 2020, p. 3960). They offer practical examples, such as human-scaled transportation (which means, for example, changing from commercial airlines to train, or from single-occupant vehicles to public transit; see Hollenhorst et al., 2014, p. 316) and balanced global tourism (instead of concentrating on the potential of proximity tourism in developed countries and emerging economies, paying attention to the situation in developing countries that are highly dependent on outbound markets; see Romagosa, 2020, p. 693).

\section{Discussion and conclusion}

The purpose of this literature review was to gain an understanding of the emerging research related to the topic of proximity tourism within the tourism and hospitality literature. Although the amount of published research on the topic is still relevantly scarce, through the review process we became convinced of the potentiality of this emerging strand of research to discuss and disrupt the basic concepts of tourism. The existing research commits to the renegotiation of tourism, its concepts and its future(s) through the five identified themes. Next, we will point out three connecting points between the themes that form the central potentials of this strand of research to widen our understanding of proximity in tourism and to create space for new conceptualisations within tourism studies that make way for "the plurality of tourism futures" (Hujbens \& Jóhannesson, 2019, p. 280).

To start with, the reviewed articles invite us to re-examine the dichotomy between tourist and local (or tourist and resident). This change happens through an acknowledgement of the diversity of touristic encounters, practices and activities and their localisations. The re-examination thus leads to a blurring of the boundaries between tourism and mundane life, which is largely a result of the increased mobility in today's global world, leading to a growth of tourism both in a traditional sense (growth of tourism consumption in numbers of, for instance, air travel and holiday accommodation) and in an experiential sense (we are increasingly engaging with touristic practices in our everyday lives and usual environments, as both consumers and producers of tourism). The reviewed literature makes visible both the increased interest towards local places and their value as "new" tourism sites as well as a desire to augment the encounters between tourists and residents in more traditional tourist spaces (considering tourists 'temporary citizens'; see Richards, 2016). In addition, the notion of 'usual environments' falls under scrutiny. Whilst tourism expands to encompass the everyday lives of our cities, blocks and neighbourhoods, the more (emotionally, affectively, segregationally) distant parts of our very own living environments and their inhabitants can become approachable through touristic practices, such as walking tours (Hoogendoorn \& Hammet, 2020).

Second, the notion of proximity challenges the definition of tourism on the basis of distance as 'nearness' and 'farness'. This challenge allows for a rethinking of the spatial ordering of 
tourism practices (Höckert et al., forthcoming) where distance does not necessarily equal physical distance in kilometres. Instead, tourists perceive distance in terms of travel costs, time and the (cultural) novelty or familiarity of a destination. Distance also includes elements of rhythms (such as speed and slowness), and it can also refer to a travel inwards, pointing to the nature of distance as an experience. This construction emphasises the significance of the journey itself the journey between physical places and the journey within - which has effects on the formation of a need for physical distance as a driver for tourism mobility (Larsen \& Guiver, 2013, p. 979). In all of this, the notion of proximity problematises conventional motives of measuring distance by tracing back to the roots of the relational nature of distance and consequently that of proximity, embracing the richness of their qualities. The articles likewise suggest reaching beyond current understandings of what counts as 'cultural proximity'. As such, the notion of cultural proximity could encompass "more than a shared language and 'cultural closeness due to common historical and cultural roots"' (Kastenholz, 2010, p. 317) and could incorporate "a sense of fascination and curiosity about a place that is both familiar yet mysterious" (Huang et al., 2013, p. 182), thus correlating with the liberating elements of the main notion of proximity as an invitation to experience the familiar anew.

Third, the potential of proximity becomes concrete through the envisioning of brave new tourism futures. The COVID-19 pandemic that has significantly stirred up current proximity tourism discussions has exposed the weaknesses of the tourism industry that is relying mostly on international tourist flows. Although the majority of the studies included here were conducted before the pandemic, the articles provide insights into how global changes, whether an economic crisis or a spreading virus, can rapidly change our everyday lives and travel opportunities due to situations that can often evolve beyond our control (AlGassim, 2021; James et al., 2017; Sharma, 2009). This has furthermore steered people's hopes and demands towards alternatives that could provide an opportunity to take a break and gain new, enjoyable experiences during times of difficulty and uncertainty (James et al., 2017). As proximity tourism is not as vulnerable to global changes as tourism dependent on international tourism flows, it could serve as an alternative strategy for international tourism and also help to tackle other issues of traditional tourism practices, such as seasonality (Diaz-Soria \& Llurdes-Coit, 2013) and negative environmental impacts (Rantala et al., 2020).

Despite the reasonably stable and accountable nature of proximity tourism, it has previously been overlooked in regional destination development processes and marketing strategies, resulting in challenges when aiming towards a better understanding of tourism on a regional level (Jeuring, 2016). Increased understanding of the potential of proximity tourism invites us to explore the relations between tourism centres and peripheries, emphasising the diversity of available experiences and thus also enhancing the development of more remote areas (Bertachhini et al., 2021). Therefore, following the views of Jeuring and Haartsen (2017), what is needed is an upgraded vision of and approach to the role of proximity tourism in tourism marketing strategies and regional development without forgetting how it can contribute to the wellbeing of residents. Furthermore, a reorientation towards the valuation of local destinations and ex- 
ploration of the possibilities of proximity tourism could offer beneficial insights into alternative tourism futures.

Finally, we acknowledge that the decision to limit our review on peer-reviewed journal articles published in English has led to a spectrum of publications being left out of the review. Furthermore, the challenges in defining the search term, resulting in leaving out "second-home tourism", "domestic tourism" and "local" from the search terms has impacted the results of this literature review. However, we feel that the thematisation of the 24 articles selected for the review has given a fruitful basis to widen our understanding of proximity in tourism, which can be elaborated further in future research.

\section{Acknowledgements}

This paper has received funding from the Envisioning Proximity Tourism with New Materialism project (Academy of Finland, no. 324493). We wish to thank the information specialists from the University of Lapland's Library Services for their generous help and the reviewers and our great proofreader from Scribendi for their insightful comments.

\section{References}

Alexander, A. C., Lee, K. H. , \& Kim, D. (2011). Determinants of visitor's overnight stay in local food festival: An exploration of staycation concept and its relation to the origin of visitors. Proceedings of the 16th Annual Graduate Education \& Graduate Student Conference in Hospitality \& Tourism, Houston, TX.

AlGassim, A. A. (2021). The effect of COVID-19 on intraregional tourism of gulf cooperation council countries. International Journal of Tourism and Hospitality, 1(1), 1-13.

Bertacchini, E., Nuccio, M., \& Durio, A. (2021). Proximity tourism and cultural amenities: Evidence from a regional museum card. Tourism Economics, 27(1), 187-204. https://doi. org/10.1177/1354816619890230

Besson, A. (2017). Everyday aesthetics on staycation as a pathway to restoration. International Journal of Humanities and Cultural Studies, 4(2), 34-52.

Biddulph, R. (2017). Tourist territorialisation and geographies of opportunity at the edges of mass destinations. Tourism Geographies, 19(1), 27-43. https://doi.org/10.1080/14616688.2016. 1217920

Bissell, D. (2018). Proximity from a distance: Virtual and imaginative mobility through the intimacies of life on screen. In Mobilities and complexities (pp. 41-47). Routledge.

Canavan, B. (2013). The extent and role of domestic tourism in a small island: The case of the isle of man. Journal of Travel Research, 52(3), 340-352. https://doi. org/10.1177/0047287512467700 
Chen, J., \& Chen, N. (2017). Beyond the everyday? Rethinking place meanings in tourism. Tourism Geographies, 19(1), 9-26. https://doi.org/10.1080/14616688.2016.1208677

Couret, C. (2020). Creative tourism - Providing the answers to a more inclusive society. Worldwide Hospitality \& Tourism Themes, 12(6), 747-751. https://doi.org/10.1108/ WHATT-07-2020-0072

Cvelbar, L. K., \& Ogorevc, M. (2020). Saving the tourism industry with staycation vouchers. Emerald Open Research, 2, Article 65. https://doi.org/10.35241/emeraldopenres.13924.1

de Bloom, J., Nawijn, J., Geurts, S., Kinnunen, U., \& Korpela, K. (2017). Holiday travel, staycations, and subjective well-being. Journal of Sustainable Tourism, 25(4), 573-588. https:// doi.org/10.1080/09669582.2016.1229323

Diaz-Soria, I. (2017). Being a tourist as a chosen experience in a proximity destination. Tourism Geographies, 19(1), 96-117. https://doi.org/10.1080/14616688.2016.1214976

Diaz-Soria, I., \& Llurdés Coit, J. C. (2013). Thoughts about proximity tourism as a strategy for local development. Cuadernos De Turismo, 32, 303-305.

Germann Molz, J. (2009). Representing pace in tourism mobilities: Staycations, slow travel and the amazing race. Journal of Tourism \& Cultural Change, 7(4), 270-286. https://doi. org/10.1080/14766820903464242

Griffin, T. (2017). Immigrant hosts and intra-regional travel. Tourism Geographies, 19(1), 44-62. https://doi.org/10.1080/14616688.2016.1169314

Hollenhorst, S. J., Houge-Mackenzie, S., \& Ostergren, D. M. (2014). The trouble with tourism. Tourism Recreation Research, 39(3), 305-319. https://doi.org/10.1080/02508281.2014.11087003

Hoogendoorn, G., \& Hammett, D. (2020). Resident tourists and the local 'other'. Tourism Geographies. https://doi.org/10.1080/14616688.2020.1713882

Huang, W., Chen, C., \& Lin, Y. (2013). Cultural proximity and intention to visit: Destination image of Taiwan as perceived by mainland Chinese visitors. Journal of Destination Marketing and Management, 2(3), 176-184. https://doi.org/10.1016/j.jdmm.2013.06.002

Hugues, F. (2009). Local differentiation of ski resorts by nearby consumers: Saint-PierredeChartreuse and Sept-Laux: Two periurban ski resorts near Grenoble. Essachess, 2(4), 29-55.

Hujbens, E. H., \& Jóhannesson, G. T. (2019). Tending to destinations: Conceptualising tourism's transformative capacities. Tourist Studies, 19(3), 279-294. https://doi. org/10.1177\%2F1468797619832307

Höckert, E., Rantala, O. \& Jóhannesson, G. T. (forthcoming). Sensitive communication with proximate messmates. Tourism Culture \&Communication.

James, A., Ravichandran, S., Chuang, N., \& Bolden III, E. (2017). Using lifestyle analysis to develop lodging packages for staycation travelers: An exploratory study. Journal of 
Quality Assurance in Hospitality \& Tourism, 18(4), 387-415. https://doi.org/10.1080/152800 8X.2016.1250240

Jeuring, J. (2017). Perspectives on proximity tourism in Fryslân. University of Groningen.

Jeuring, J. H. G. (2016). Discursive contradictions in regional tourism marketing strategies: The case of Fryslân, The Netherlands. Journal of Destination Marketing \& Management, 5(2), 65-75. https://doi.org/10.1016/j.jdmm.2015.06.002

Jeuring, J. H. G. (2018). Pluralising touristic production and consumption roles of residents? An SME perspective on proximity tourism. Tourism Recreation Research, 43(2), 147-160. https:// doi.org/10.1080/02508281.2017.1410973

Jeuring, J. H. G., \& Haartsen, T. (2017). The challenge of proximity: The (un)attractiveness of near-home tourism destinations. Tourism Geographies, 19(1), 118-141. https://doi.org/10.1080 /14616688.2016.1175024

Jeuring, J. H. G. \& \& Diaz-Soria, I. (2017). Introduction: Proximity and intraregional aspects of tourism. Tourism Geographies, 19(1), 4-8. https://doi.org/10.1080/14616688.2016.1233290

Kaaristo, M., \& Rhoden, S. (2017). Everyday life and water tourism mobilities: Mundane aspects of canal travel. Tourism Geographies, 19(1), 78-95. https://doi.org/10.1080/14616688.2016.1230 647

Kastenholz, E. (2010). 'Cultural proximity' as a determinant of destination image. Journal of Vacation Marketing, 16(4), 313-322. https://doi.org/10.1177/1356766710380883

Kennedy, A. (2009). Regional staycations. Palaestra, 24(4), 43-47.

Larsen, G. R., \& Guiver, J. W. (2013). Understanding tourists' perceptions of distance: A key to reducing the environmental impacts of tourism mobility. Journal of Sustainable Tourism, 21(7), 968-981. https://doi.org/10.1080/09669582.2013.819878

Llurdés, J. C., Diaz-Soria, I., \& Romagosa, F. (2016). Mining heritage and proximity tourism: Exploring synergies, The case of Cardona. [Patrimoni miner i turisme de proximitat: Explorant sinergies, El cas de Cardona]. Documents D'Analisi Geografica, 62(1), 55-77. https:// doi.org/10.5565/rev/dag.231

Nemec-Loise, J. (2014). How I spent my summer staycation. Children \& Libraries: The Journal of the Association for Library Service to Children, 12(3), 31-32. https://doi.org/10.5860/cal.12n3.31

Nuottila, J., Jutila, S., \& Hakkarainen, M. (2017). Kirjallisuuskatsaus: Matkailun jakamistalous vastuullisuuden viitekehyksessä. Matkailututkimus, 13(1-2), 53-70. https://journal.fi/ matkailututkimus/article/view/67854

Pawłowska-Legwand, A., \& Matoga, Ł. (2016). Staycation as a way of spending free time by city dwellers: Examples of tourism products created by local action groups in lesser Poland voivodeship in response to a new trend in tourism. World Scientific News, 51 . 
Pokorny, H., Holley, D. , \& Kane, S. (2017). Commuting, transitions and belonging: The experiences of students living at home in their first year at university. Higher Education, 74(3), 543-558. https://doi.org/10.1007/s10734-016-0063-3

Rantala, O., \& Puhakka, R. (2019). Lasten ja nuorten luontoyhteyden vahvistamisesta perusta tulevaisuuden lähimatkailulle. Matkailututkimus, 15(1), 93-96. https://doi.org/10.33351/ mt. 84347

Rantala, O., Salmela, T., Valtonen, A., \& Höckert, E. (2020). Envisioning tourism and proximity after the Anthropocene. Sustainability, 12(10), 3948-3964. https://doi.org/10.3390/su12103948

Richards, G. (2016). Tourists in their own city: Considering the growth of a phenomenon. Tourism Today, 16, 8-16.

Romagosa, F. (2020). The COVID-19 crisis: Opportunities for sustainable and proximity tourism. Tourism Geographies, 22(3), 690-694. https://doi.org/10.1080/14616688.2020.1763447

Räikkönen, J., Marjanen, H., Kohijoki, A.-M., \& Lahovuo, I. (2018). Matkailuelämyksiä ilman matkaa? Fokusryhmätutkimus matkailutyyppisestä kulutuksesta osana kuluttajan arkea. Matkailututkimus, 14(2), 24-43. https://journal.fi/matkailututkimus/article/view/77387

Sharma, S. (2009). The great American staycation and the risk of stillness. M/C Journal, 12(1).

Szytniewski, B. B., Spierings, B., \& van der Velde, M. (2017). Socio-cultural proximity, daily life and shopping tourism in the Dutch-German border region. Tourism Geographies, 19(1), 63-77. https://doi.org/10.1080/14616688.2016.1233289

Urry, J. (2002). The tourist gaze (2nd ed.). Sage.

Tuan, Y. F. (1990). Topophilia: A study of environmental perception, attitudes and values. Columbia University Press. 